\title{
A Solar Powered PWM Charger for Multiport USB Devices
}

\author{
A. A. Willoughby \\ Department of Physics, Covenant University, Ota, Ogun State, Nigeria
}

\begin{abstract}
The circuit presented is a solar photovoltaic PWM charger for charging USB-powered devices. It is intended as a portable and tidier substitute to the commonly assembled petrol generator powered multi-socket AC phone chargers displayed in market stalls in Nigeria. The unit consists of two DC-DC step-down buck converter circuits; the first employs a TL494 switchmode regulator to charge a $12 \mathrm{~V} / 24$ Ah battery in constant current, constant voltage mode, while the second is based around multiple MC34063 switchmode ICs, each configured as a $5 \mathrm{~V}$ buck converter to run USB devices such as iPads, iPods, MP3 players, Bluetooth devices as well as chargers for mobile phones.
\end{abstract}

Keywords: Buck Converter, Constant Current-Constant Voltage, Pulse Width Modulation, Switch mode regulator, solar PV, USB devices.

\section{Introduction}

Nigeria is currently beset with problems of AC power generation, transmission and distribution which continue to be frustrating and defiant of the efforts to improve and modernise the three departments. Most urban homes on the grid can be without power for days and options available for AC generation are petrol/diesel generators and inverters [17]. With the mobile telecoms industry and social network apps well established, there is now a proliferation of USB devices and accessories. Nowadays a family home can be sure to have mobile phones and other USB devices such as iPad, iPod, MP3, Bluetooth device, etc, all of which run on 5 V DC, so it is quite frustrating when there is no power to recharge the batteries in these devices. Business offices, city and rural markets often times experience power cuts for long hours of the day, consequently hampering business transactions which otherwise would have been accomplished via mobile phones and the internet. Local entrepreneurs have capitalized on power cuts by providing a solution of sorts whereby an array of 13 Amp mains sockets ranging in number from a dozen to twenty or more are and connected in parallel and arranged on a flat wooden platform from which mobile phones can be charged by means of their AC plugs (Photo 1). The contrivance is supplied with power from a petrol generator positioned next to the stand and right in the middle of the market. This is primitive and poses a health hazard, considering that exhaust fumes of carbon monoxide from the generator is being released into the environment where perishable foodstuff and grains are being sold. Aside from polluting the environment, it also constitutes a respiratory hazard to the provider and surrounding traders.

Nigerians are now becoming educated, albeit, at a slow pace, on the benefits of harnessing the sun's abundant energy in order to meet their energy demands because of the escalating cost of grid electricity, the exorbitant cost of fueling and maintaining petrol/diesel generators and other inauspicious reasons [17]. By virtue of its position along the equatorial belt, Nigeria is naturally well endowed with renewable energy resources, including solar resource; it has an annual average daily solar radiation of about $5.25 \mathrm{kWh} / \mathrm{m}^{2}$ per day varying between $3.5 \mathrm{kWh} / \mathrm{m}^{2}$ per day at the coastal areas and $7.0 \mathrm{kWh} / \mathrm{m}^{2}$ per day at the Northern boundary, and an annual average daily sunshine of $6.25 \mathrm{hrs}$ ranging between $3.5 \mathrm{hrs}$ at the coastal areas and $9.0 \mathrm{hrs}$ at the far northern boundary [14], [15].

These observations are the inspiration for this work - the design and construction of a simple multiport USB hub for charging mobile phones and other USB devices from a solar photovoltaic power source. To achieve this aim, an affordable cost effective but efficient solar charger is needed to charge a deep cycle battery during the sun hours of the day, supplying power to several USB charging ports. The product can be used in the home, business offices, rural dwellings and as a commercial venture where people pay to have their phones charged. It is an excellent replacement for the locally fabricated generator powered chargers shown in the pictures in Photo 1 below. From a financial viewpoint, the circuit components are cheap and readily available. 

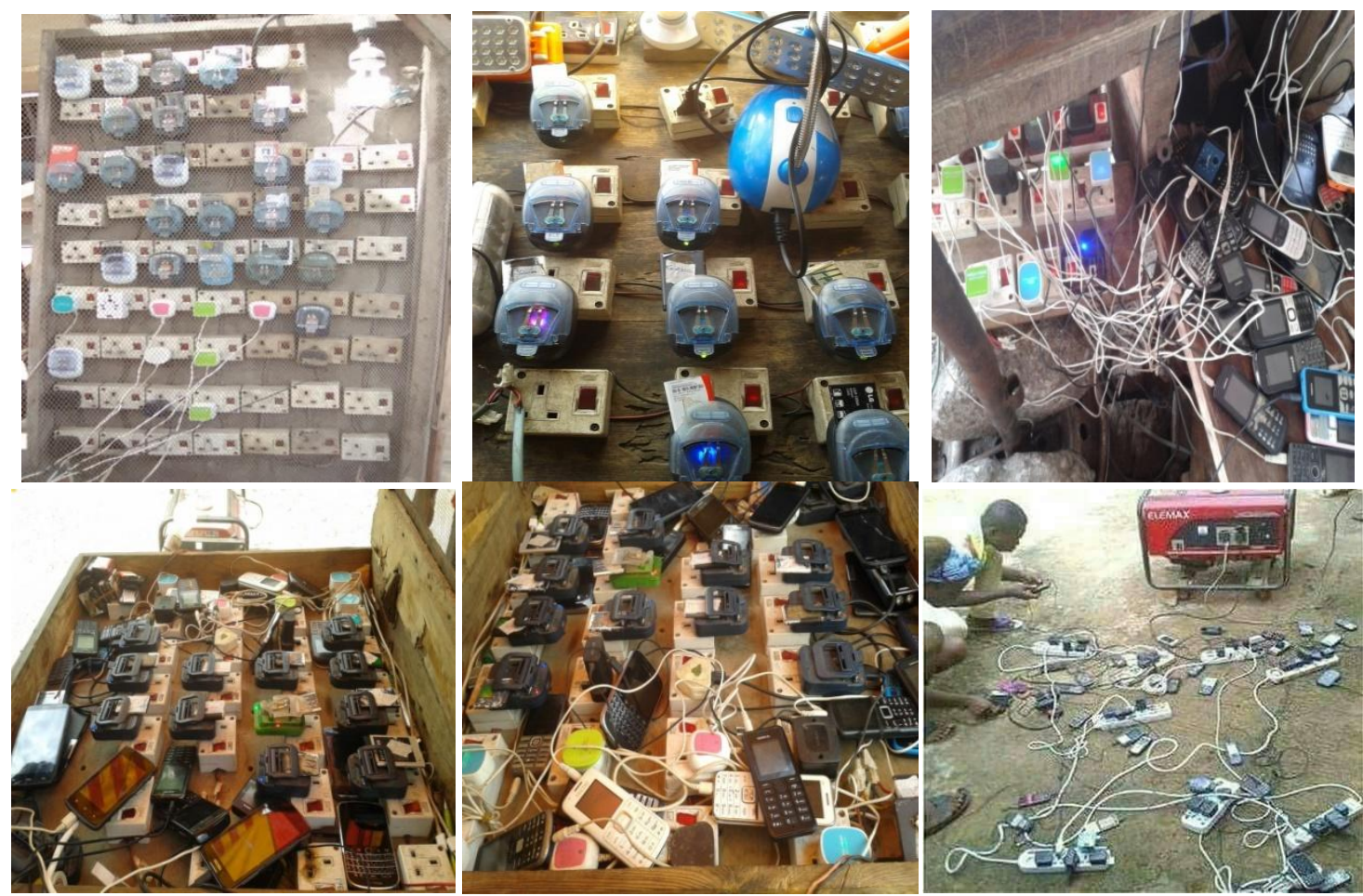

Photo 1. Mobile phone chargers powered by petrol generators in market stalls

\section{Circuit Details}

Fig.1 shows the block diagram of the hardware comprising the PV module, charger, the deep cycle battery and the $5 \mathrm{~V}$ buck converters. Two different Pulse Width Modulation (PWM) switching circuits are contained in this project: the first, the main battery charger, is based around the versatile TL494 switch mode chip configured as a constant current, constant voltage (cc-cv), $22 \mathrm{~V}$ to $14 \mathrm{~V}$ DC-DC step down converter; the second employs an MC34063 switch mode regulator configured as a $12 \mathrm{~V}$ to $5 \mathrm{~V}$ DC-DC buck converter for charging most USB devices such as iPads, iPods, MP3s, as well as mobile phones. The design in this work has been restricted to eight USB ports, although the ports can be extended to as many as ten or more with the ampere-hour capacity of the battery taken into consideration.

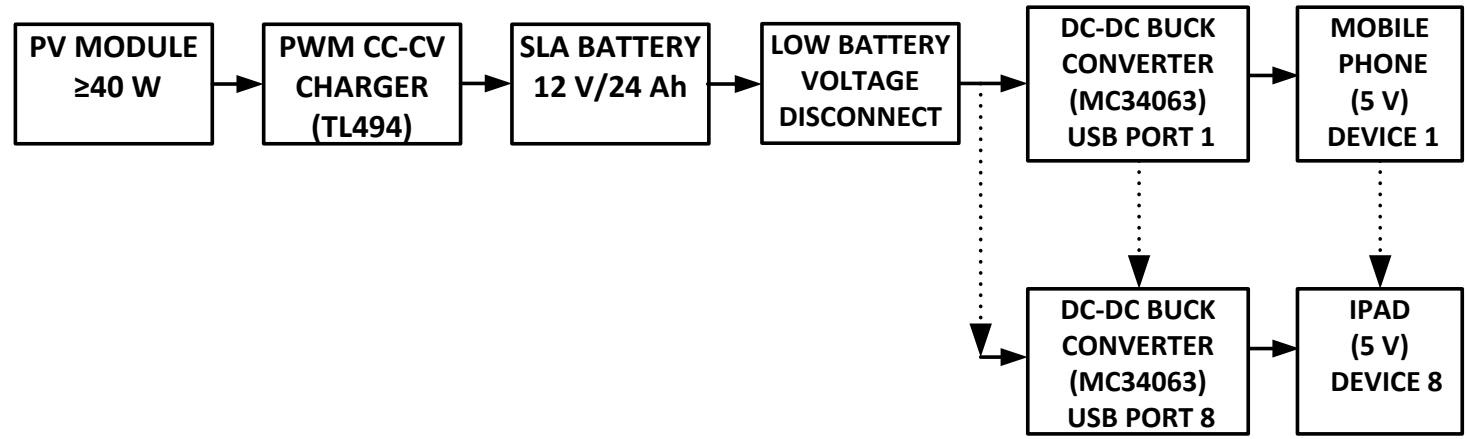

Fig. 1 Block Diagram of the solar PV powered PWM USB charger circuit

\subsection{The main battery charger}

\section{Circuit Operation}

The main battery charger is shown in Fig.2. Literature on the internal configuration and pin functions of the TL494 chip are outlined in the following articles: [1] - [4]. The TL494 (IC1) is a fixed frequency PWM controller containing two error amplifiers, a sawtooth waveform generator and a $5 \mathrm{~V}$ reference, $\mathrm{V}_{\mathrm{REF}}$. It also contains a dead time control comparator, and output control options for single ended or push- pull action. Single ended operation has been utilized in this circuit. The circuit is configured as a step-down (buck) switching converter, where a $22 \mathrm{~V}$ solar module is converted to a lower regulated voltage of about $14 \mathrm{~V}$ to charge the main battery. 


\subsection{TL494 Buck converter and cc-cv operation}

Discussion on the theory and functionality of the TL494 buck converter topology shown in Fig. 2 below and design equations for calculating required parameters was discussed in a previous work, [17] and can also be found in the following references, [5] - [10]. In this circuit, the external op amp current amplifier employed in the previous work has been discarded and the internal error amp2 in the TL494 with input pins 15 and 16 utilized instead.

Charge current is measured off the battery via voltage developed across R17 and taken into noninverting input, pin 16 of the internal comparator via R16. This voltage is compared with that at the inverting input, pin 15:

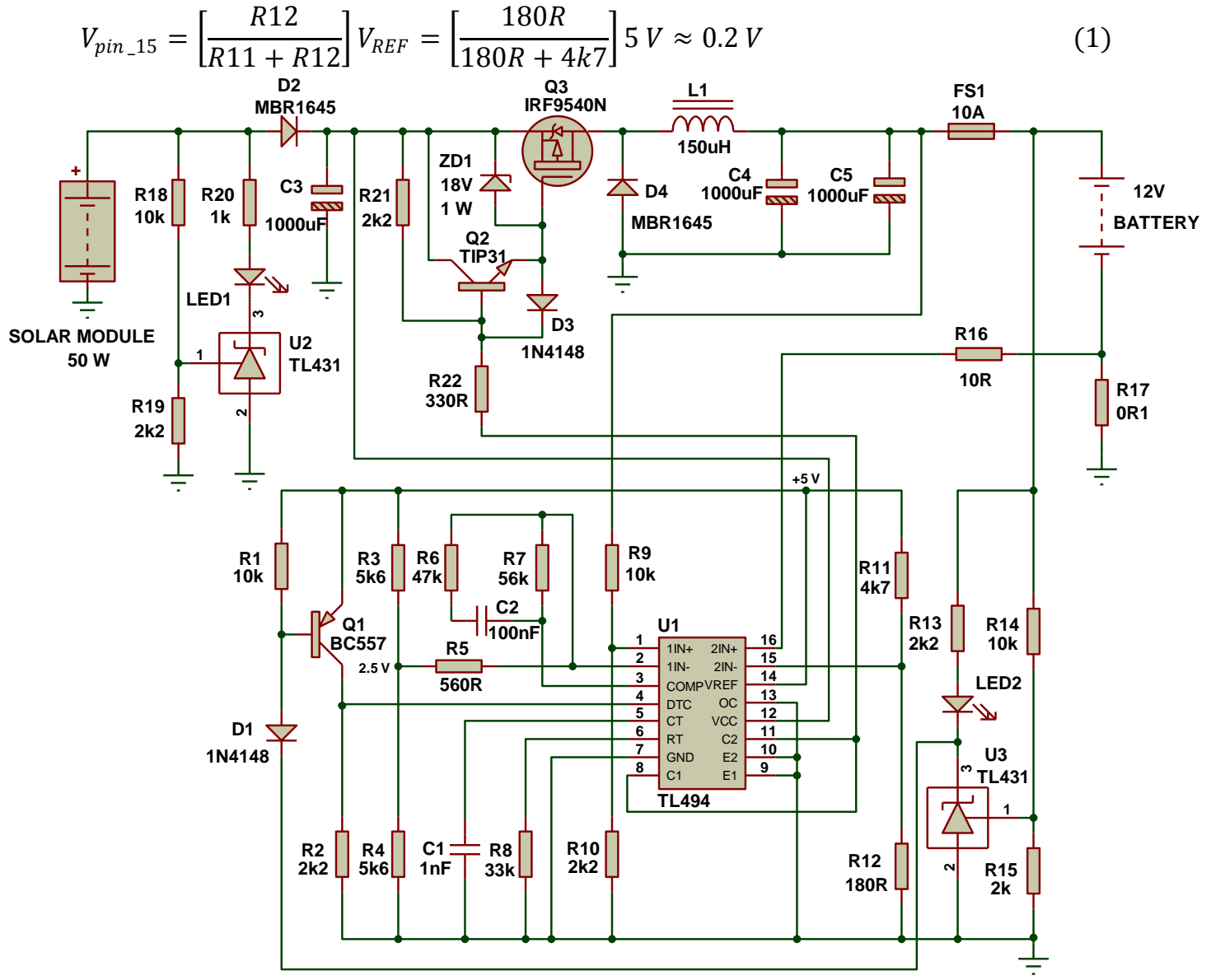

Fig. 2 Circuit diagram of the cc-cv buck converter battery charger

Initially, a discharged battery will draw a large current and if the voltage developed across R17 is greater than $0.2 \mathrm{~V}$, then non-inv. input, pin $16>$ inv. input pin 15 . The output of the internal comparator will be HIGH and this in turn will force the width of the output pulses of the TL494 to shrink, hence reducing charging current through MOSFET Q3.

U2, R18, R19, R20 and LED1 monitor the solar radiation level. The circuitry indicates when a sufficient charging voltage is reached. This voltage is set at $14 \mathrm{~V}$ by the potential divider R18/R19. TL431 reference regulator U2's reference mode (pin 1), $V_{R E F}$, is connected to the potential divider and with the values given, when its reference node, pin 1 reaches $V_{R E F}=2.5 \mathrm{~V}, \mathrm{U} 1$ conducts, its cathode, pin 3, is taken to ground so that LED1 switches on. This occurs when the solar module voltage is $\geq 14 \mathrm{~V}$, i.e.,

$$
V_{\text {OUT }}=V_{R E F}\left[1+\frac{R 18}{R 19}\right]=2.5\left[1+\frac{10 k}{2 k 2}\right] \approx 14 \mathrm{~V}
$$

$\mathrm{U} 3$ and its associated components, R14, R15, R13, LED2 in conjunction with Q1, D1 and R1 provide an overvoltage protection. Q1 collector is connected to the dead-time control, pin 4 of the TL494 which is held low under normal, safe voltage. If the output voltage should rise to the point that $2.5 \mathrm{~V}$ is developed at the reference node, $V_{R E F}$, of U3; the device conducts, grounding the cathode and consequently forward biasing Q1 base. Pin 4 is pulled high, up to VREF, shutting down U1's output pulses and hence disabling its output transistors. R14 and R15 monitor this output voltage, fixing $V_{R E F}$ at $2.5 \mathrm{~V}$. 


\subsection{Low Battery Disconnect Circuit}

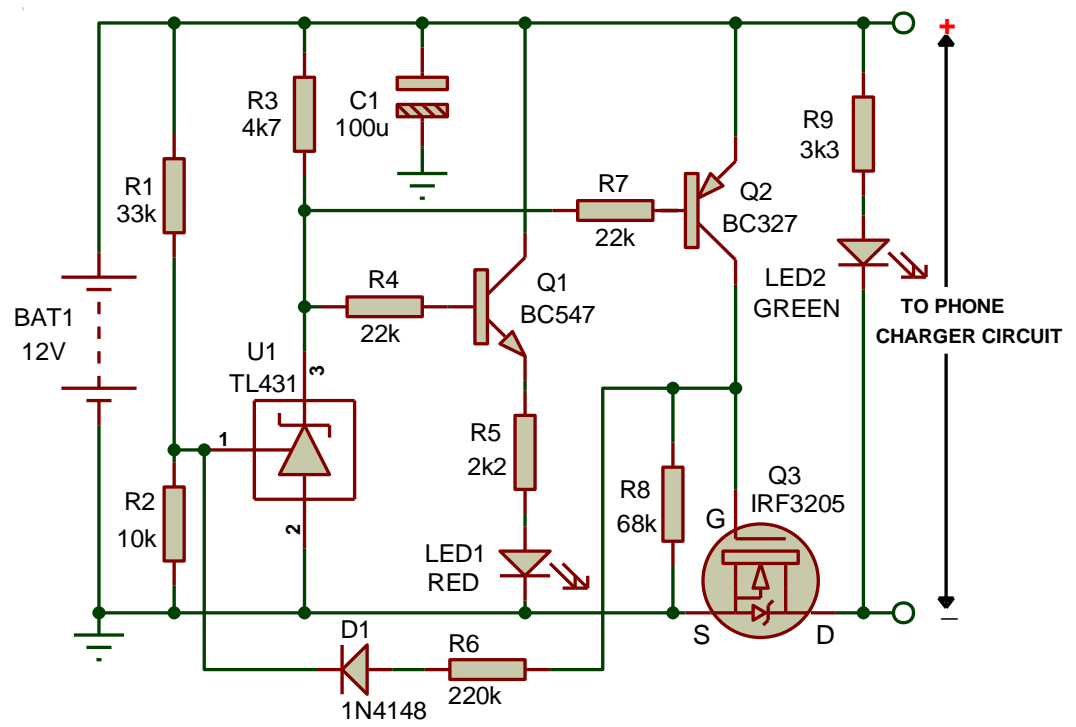

Fig. 3 Circuit diagram of the battery low voltage disconnect

Fig. 3 shows the battery undervoltage disconnect circuit. This circuit prevents the battery from deep discharge by disconnecting the battery power from the eight phone charging circuits. Again, the TL431 reference regulator U1's reference mode (pin 1) is connected to a potential divider consisting of R1 and R2, [11]. Applying equation (2) and replacing the resistors with R1 and R2, the low voltage threshold is set at $\approx 11$ $\mathrm{V}$. Whenever the battery voltage is above $11 \mathrm{~V}$, i.e. reference voltage $V_{R E F}=2.5 \mathrm{~V}$ reached, U1 conducts, its cathode (pin 3) is pulled low biasing Q2 base and switching it on. This in turn switches on power MOSFET Q3, which passes current to the eight phone charging circuits. Green LED2 lights up indicating 'Battery Good'. If the battery voltage drops to $11 \mathrm{~V}$, the TL431 $V_{R E F}$ drops below $2.5 \mathrm{~V}$, its cathode goes high switching off Q2 and hence Q3 so that power to the circuits is disconnected. LED1 is switched off. At the same time, the 'HIGH' at U1's cathode turns Q1 on, turning on red LED1 and indicating low voltage. R6 and D1 provide some level of hysteresis.

\subsection{MC34063 regulator /Charger}

Desktop computer USB 2.0 ports deliver about 500mA for a range of voltages between $4.8 \mathrm{~V}$ and 5.4 V. Most phones work comfortably within this range. Switching regulators such as the 5-pin MC34167, LM2574/5/6 or LM2595/6, [18] monolithic ICs in TO-220 packages are designed for use in DC-DC buck or buck/boost converter topologies requiring precisely fixed or adjustable output voltages. Basically, they require just four main support components: a Schottky diode, an inductor and input and output capacitors and would be more than adequate for this project. In terms of cost, MC34063 is preferred because it is cheaper, readily available and can be configured as a DC to DC $5 \mathrm{~V}$ buck converter. The details of its internal structure are described in the following articles [12], [13]. The output voltage can be made adjustable via two external resistors with high reference accuracy. A minimum number of external components are connected as shown in the circuit Figs. $4 \mathrm{a}$ and $4 \mathrm{~b}$. The theory of operation and calculation of parameters can be found in [5] - [10]. Pin 5 is the comparator inverting input (CII) and is maintained at $1.25 \mathrm{~V}$ reference. The $470 \mathrm{pF}$ timing capacitor sets the switching frequency to approximately $50 \mathrm{kHz}$. Current limiting resistor, Rsc is calculated from the MC34063 datasheet, [13], and [14] to be $0.3 \Omega$. The chip compares the output with the $1.25 \mathrm{~V}$ reference at pin 5 . To achieve a $5 \mathrm{~V}$ output, the output voltage is attenuated to $1.25 \mathrm{~V}$ at pin 5 via a voltage divider network made up of R1 and R2. The output voltage is obtained from

$$
V_{\text {OUT }}=V_{R E F}\left[1+\frac{R 1}{R 2}\right]=1.25\left[1+\frac{3 k}{1 k}\right]=5 \mathrm{~V}
$$

LED1 indicates $5 \mathrm{~V}$ at the output of the converter. A current detecting indicator that shows if current is actually flowing through the battery is provided by transistor Q1, R5, R6 and LED2. When the phone to be charged is connected to the female USB A socket, the base-emitter voltage of Q1 exceeds $0.6 \mathrm{~V}$ as a result of current flowing through R6. Q1 conducts and LED2 is switched on, signifying that charging is ongoing. At first the LED is bright. After some charging time, its intensity begins to dim as less current is being demanded by the battery of the device. When the phone is sufficiently charged, the base-emitter voltage drops well below $0.6 \mathrm{~V}$, Q1 switches off and so does LED2 to indicate that the battery is charged. The 1N5819 Schottky diode D1, 
shown in Fig.4a delivers a forward current of $1 \mathrm{~A}$ at a voltage drop of $0.4 \mathrm{~V}$ although a maximum value can be restricted to $600-700 \mathrm{~mA}$.

If it is assumed that a port delivers an average of $500 \mathrm{~mA}$, then in one hour, total current consumption by eight (or more) devices would be $4 \mathrm{~A}$ or more. For a continuous depletion of current at this rate and nonstop charging of the main supply battery during the day, which will be interspersed with overcast and cloudy conditions, a $\geq 40 \mathrm{~W}$ photovoltaic panel and a 24 Ah battery are adequate to supply desired power to the devices. Fig. 6 shows the output characteristics of a $60 \mathrm{~W}$ solar PV used for the experiment [16]. Short circuit currents at irradiation levels of $\mathrm{G}=450$ and $570 \mathrm{~W} / \mathrm{m}^{2}$ are about 1.4 and $1.8 \mathrm{~A}$, ample values necessary to satisfactorily charge the 24 Ah battery throughout the day.

The USB charging circuitry consists of ports $1-8$. Each port is switched on by an independent switch. Not all USB devices have similar power consumption. Some mobile phones require charging currents of 400 to $500 \mathrm{~mA}$, while the bigger iPads or Tablets consume over 2 A. The MC34063 chip outputs a current of 1.5 A. To obtain higher output currents, D1 is replaced with a 1N5822 (3 A) and an external power MOSFET driver connected to output pin 2 of the MC34063 IC (Fig.4b). Fig. 5 shows the Proteus 3-D visualizer of the prototype with component layout while Photo 2 shows a picture of the final PCB hardware with component assembly. In the photo, the TO-220 devices are not visible because they have been soldered on to the underside of the single sided PCB for convenient placement on a heatsink.

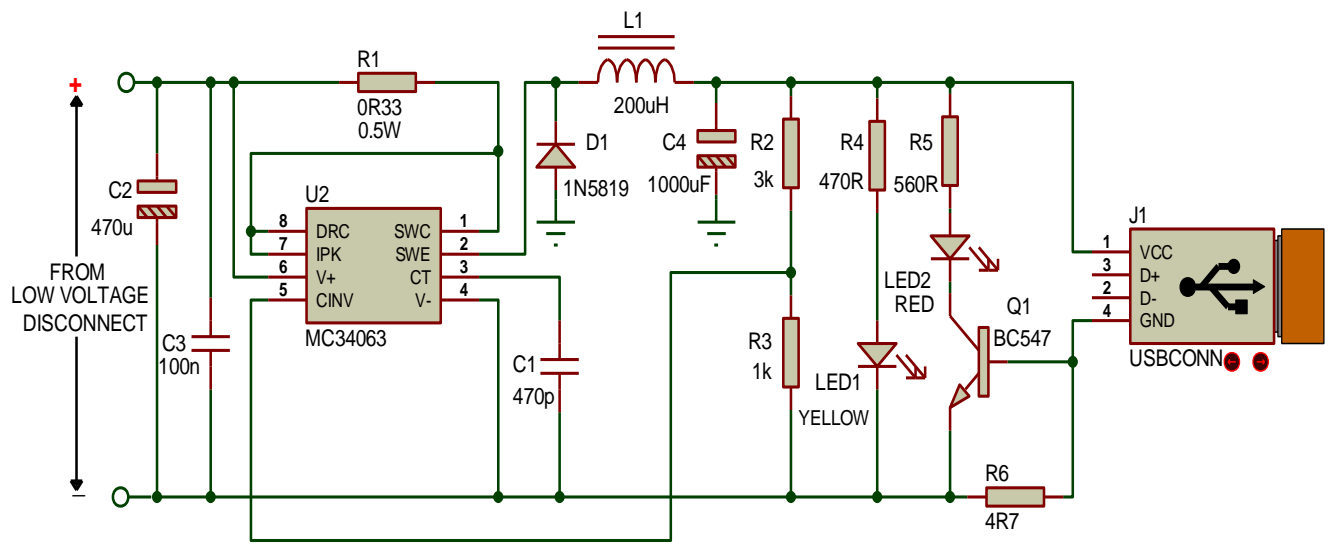

Fig. 4a MC34063 buck converter phone charger for the USB ports

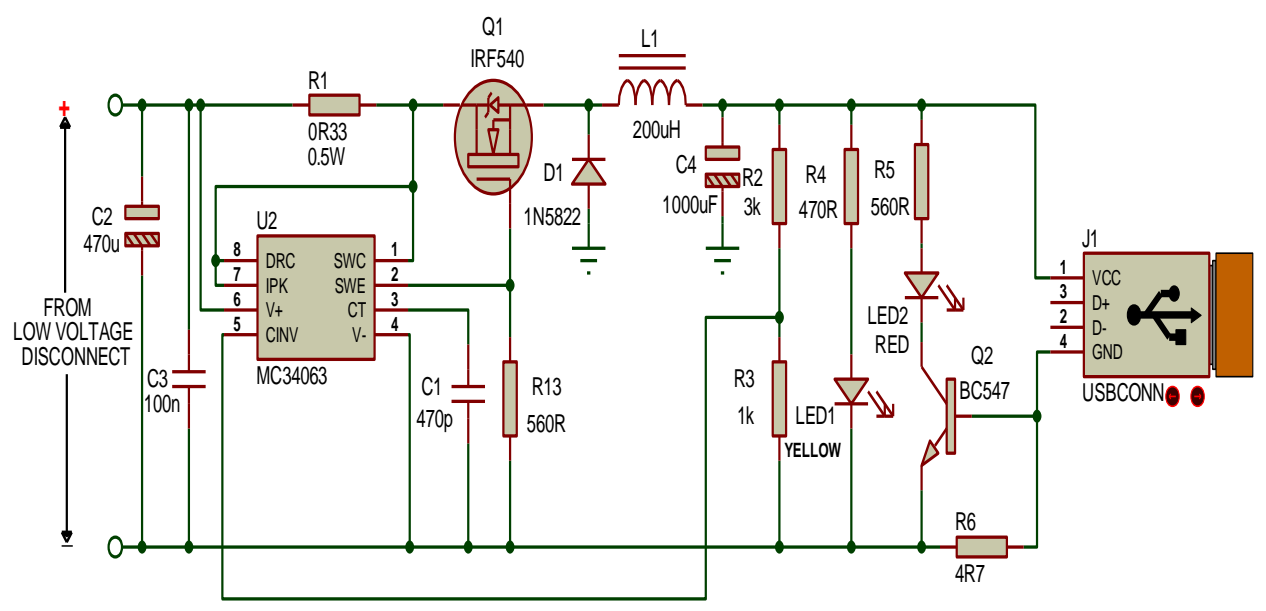

Fig. 4b MC34063 buck converter with external MOSFET driver 


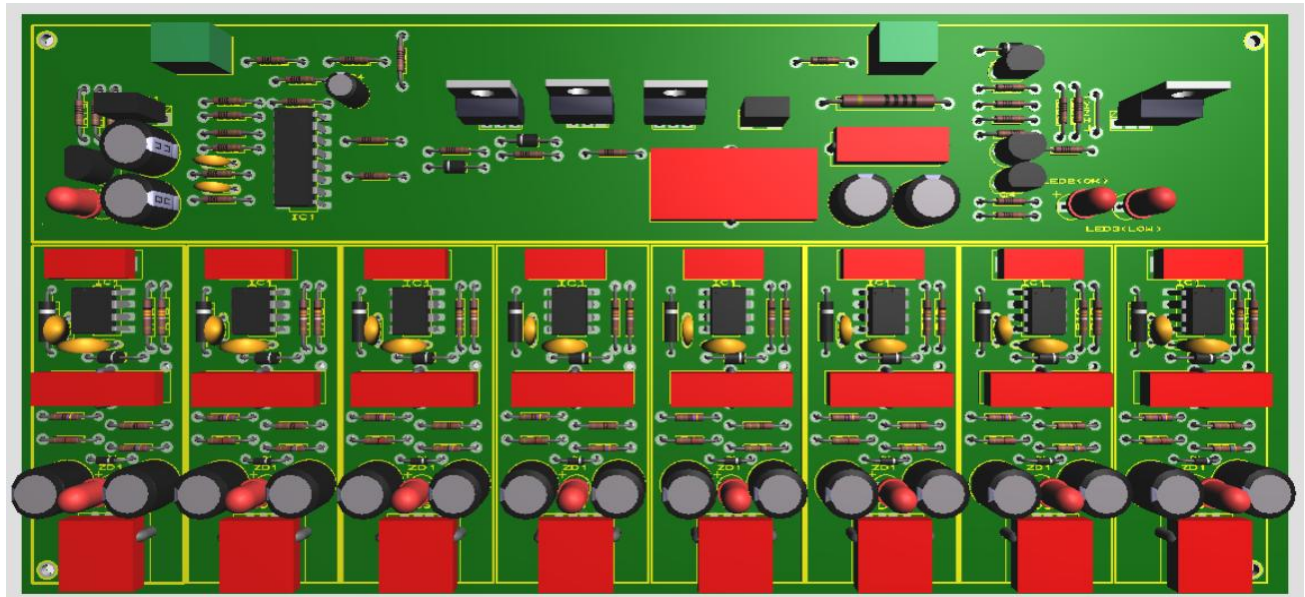

Fig.5 Proteus 3D visualizer of the circuit PCB layout (Figs. 3 \& 4a)

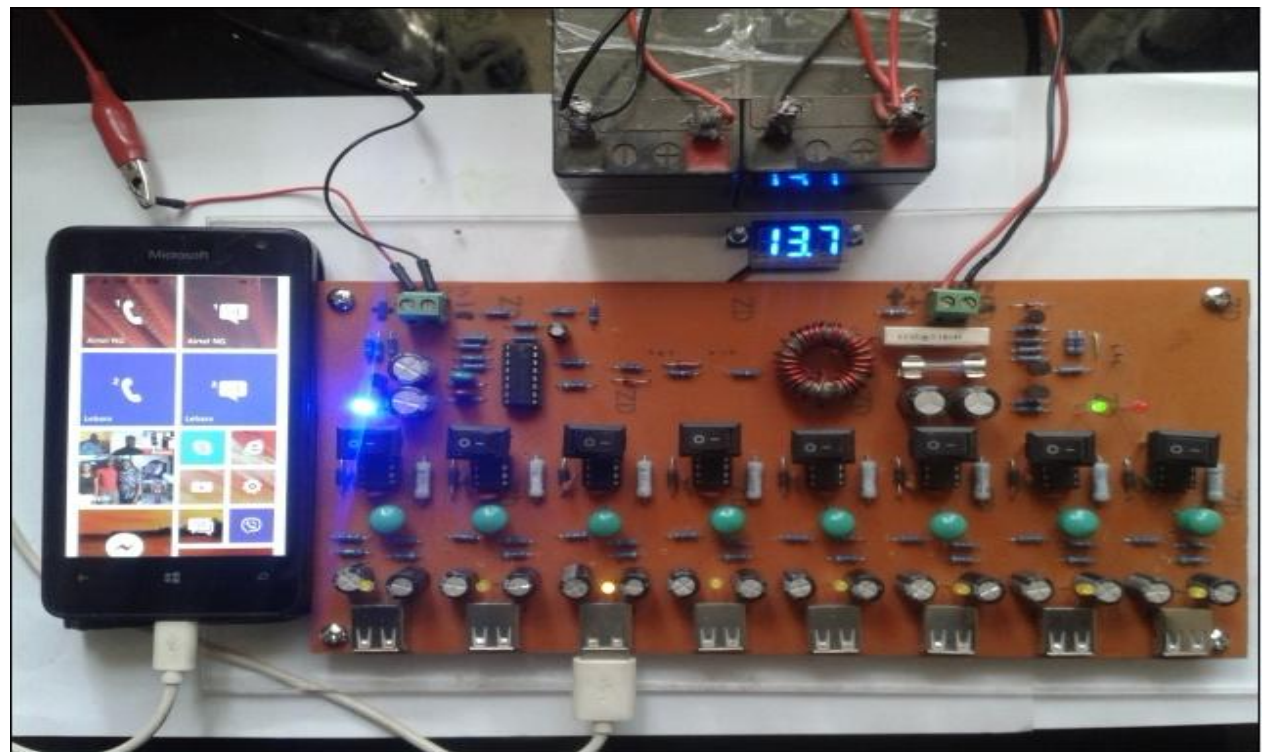

Photo 2. Photo of finished PCB circuit assembly

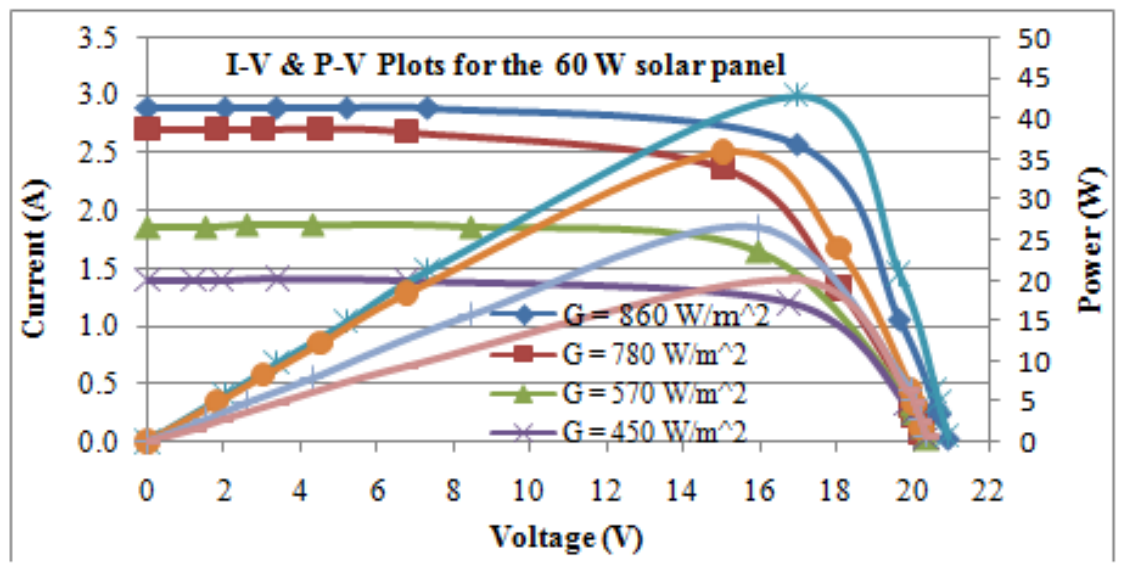

Fig.6 Current-Voltage and Power-Voltage characteristics of a $60 \mathrm{~W}$ solar panel used for the prototype

\section{Conclusion}

A solar PV powered hub for charging USB-powered devices has been presented. The proposed low cost, high performance circuit, in PWM switching mode, was implemented for efficient charging of the battery as well as the USB devices. The notable advantage of this device over the petrol powered generator supply can be seen in the portability of the device, charging efficiency and alternate use of renewable energy rather than 
fossil fuel as a means of finding eco solutions to environmental challenges. The product will find application and usefulness in charging USB devices found in diverse places like homes, offices, clubs, markets and rural areas. A proposal for a future upgrade is to implement the circuit using smd components for compactness and a microcontroller such as the Arduino ATmega328 or PIC for a 'smart system'. The microcontroller can then monitor charging modes (bulk, absorption float), overloads, under-voltage, etc, and subsequently display those parameters on an LCD.

\section{References}

[1]. TL494 Switch mode pulse width modulation control circuit. ON Semiconductor. [Online] Available at http://onsemi.com [Accessed November 16, 2007].

[2]. P. Griffith, Designing Switching Voltage Regulators with the TL494 Application Report SLVA001D. Texas Intruments. Rev. [Online] Available at: www.ti.com/lit/an/slva001e/slva001e.pdf [Accessed November 16, 2007].

[3]. J.H. Alberkrack, A simplified power supply design using the TL494 control circuit, AN983/D. [Online] Available at http://onsemi.com [Accessed October 22 2007].

[4]. I. Ozkaynak, Theory of operation of Ni-MH Battery Charger. [Online] Available at: http://powerelectronics.com/sitefiles/powerelectronics.com/files/archive/powerelectronics.com/mag/606PET25.pdf [Accessed April 4, 2015].

[5]. D. Schelle, and J. Castorena, Buck-Converter Design Demystified Power Electronics Technology. [Online] Available at: http://powerelectronics.com/site-files/powerelectronics.com/files/archive/powerelectronics.com/mag/606PET25.pdf [Accessed April 4, 2015].

[6]. B. Hauke, (2012) Basic Calculation of a Buck Converter's Power Stage. Texas Instruments Application Report SLVA77A. [Online] Available at: http://www.ti.com/lit/an/slva477a/slva477a.pdf [Accessed April 8, 2015].

[7]. Ejury, J. (2013) Buck Converter Design. Infineon Technologies North America (IFNA) Corp. [Online] Available at: http://www.mouser.com/pdfdocs/buckconverterdesignnote.pdf [Accessed April 8, 2015]

[8]. ROHM Semiconductor (2012) Inductor Calculation for Buck Converter IC, No.12027ECY01.[Online] Available at: http://rohmfs.rohm.com/en/products/databook/applinote/ic/power/switching_regulator/inductor_calculation_appli-e.pdf [Accessed April 8, 2015

[9]. Texas Instruments Free Tool: Component Calculator for Buck Converters. [Online] Available at: http://www.ti.com/tool/buckconvcalc. [Accessed April 6, 2015]

[10]. Daycounter Inc. (2004) Buck Switching Converter Design Equations. .[Online] Available at: http://www.daycounter.com/LabBook/BuckConverter/Buck-Converter-Equations.phtml [Accessed April 6, 2015].

[11]. TL431 Programmable Precision References. [Online] Available at http://onsemi.com [Accessed November 25, 2007].

[12]. MC34063 DWS. Design spreadsheet for the MC33063 device in stepdown topology, Available at: http://wwwonsemi.com/pub/Collateral/MC34063 DWS.XLS. [Accessed July 13, 2014].

[13]. MC34063 DC/DC Converter control circuits. STmicroelectronics. Available at: http://www.st.com/tool/buck-convcalc. [Accessed July 13, 2014].

[14]. D. Abdulsalam, I. Mbamali, M. Mamman and Y.M. Saleh, An Assessment of Solar Radiation Patterns for Sustainable Implementation of Solar Home Systems in Nigeria. American International Journal of Contemporary Research, 2(6), 2012, 238243.

[15]. C.O. Nwokocha, T.C. Chineke, and A.B. Fabenro, (2012) Renewable energy potentials for Nigeria: Making the transition from oil and gas to solar. Prime Journal of Physical Science. 1(4), 2012, 31-39.

[16]. A.A.Willoughby, T.V. Omotosho, and A.P. Aizebeokhai, A simple resistive load I-V curve tracer for monitoring photovoltaic module characteristics. The Fifth International Renewable Energy Congress, (IREC), Hammamet, Tunisia, 2014, 14-PVE-75-P9781-4799-2195-9/14/\$31.00@2014IEEE.

[17]. A. A. Willoughby and O.A. Bablola. A Cost Effective Solar Charge Controller and Load Driver for DC Home Appliances. IOSR Journal of Electrical and Electronics Engineering (IOSR-JEEE), Volume 10, Issue 5 Ver. II (Sep - Oct. 2015), PP 92-100

[18]. 7-port USB hub with improved power output. Available at: http://www.illuwatar.se/project_pages/usb-hubb/usbhub.htm. [Accessed September 9, 2015] 